\title{
AN ECONOMIC EVALUATION OF JOHNE'S DISEASE (PARATUBERCULOSIS) IN THE DAIRY HERD USING DYNAMIC PROGRAMMING
}

\author{
AW Stott, GJ Jones, RW Humphry \& GJ Gunn \\ Epidemiology Unit, Scottish Agricultural College Veterinary Science Division, Inverness, Scotland. IV2 4JZ; \\ Telephone - $0044(0) 1463243030$ \\ Facsimile - 0044 (0)1463 243030; e-mail - g.gunn@ed.sac.ac.uk
}

The objective of this study was to estimate the loss due to paratuberculosis (PTB) for dairy herds in Great Britain (GB). PTB is an infectious and fatal enteritis of cattle. We discovered that there are two main constraints to an economic analysis of PTB for the dairy sector. Firstly the necessary epidemiological data is lacking. Secondly the long time course of the epidemic makes a static economic analysis such as that described by McInerney (1987) unsuitable. We therefore applied the dynamic programming (DP) methodology reviewed by Kennedy (1986) who listed the algorithms used in this study.

DP can be used to establish the returns to milk production in the long term under given physical and financial assumptions. As PTB primarily affects adult cows over a protracted period, the DP provides an appropriate framework for economic analysis. By altering the assumptions to represent an infected herd, the economic effects of the disease can be obtained by comparison with a control herd. It allows voluntary culling to be treated as the control expenditure undertaken in response to the output losses due to PTB. As voluntary culling is optimised, the extra control expenditure (culling) due to PTB is exactly balanced by the output losses saved (e.g. less clinical cases because more cows are culled before symptoms are observed) thus establishing the optimum point on the loss-expenditure frontier envisaged by McInerney (1987).

Our DP objective was to maximise the expected net present value (ENPV) from a current heifer and its successors over a series of 20 annual stages. For convenience, our ENPV was expressed as an annuity equivalent of $£ 26$ per cow per year for a 100 -cow herd with a GB cost of £10M. This loss suggests that PTB is of relatively minor concern compared with other sources of loss. In addition the loss due to PTB showed extreme sensitivity to falling milk price. At $£ 0.185 / 1$ the loss represent about $10 \%$ of the annuity from dairying whereas at $£ 0.165 / 1$ this has fallen to less than $3 \%$. This suggests that there is now less incentive to control the disease at farm level Farmers will be discouraged from taking action against PTB if the down turn in milk prices persists.

\section{References}

Kennedy, J.O.S. (1986). "Dynamic Programming: Applications to Agriculture and Natural Resources," Elsevier Applied Science, London.

McInerney, J. P. (1987). An economist's approach to estimating disease losses. In "Disease in Farm Livestock:Economics and Policy," (K. S. Howe and J. P. McInerney, eds.), Commission of the European Communities, pp. 25-60.

\section{Acknowledgements}

SERAD provide financial support to SAC, and MAFF funded this study. 